\title{
The heavy metal genre in an Islamic city of Padang: struggle and promotion
}

\section{Endrizal Ridwan ${ }^{1}$, Bardi Rahmawan ${ }^{2}$}

Universitas Andalas ${ }^{1}$, Universitas Andalas ${ }^{2}$

eridwan@eb.unand.ac.id ${ }^{1}$, brahmawan2020@gmail.com²

DOI: $10.18326 /$ attarbiyah.v6i1.1-14

$\begin{array}{lcc}\text { Submitted: } & \text { Accepted: } & \text { Published: } \\ \text { 2 May 2021 } & \text { 14 July 2021 } & \text { 17 July 2021 }\end{array}$

\begin{abstract}
A qualitative research was conducted on how heavy metal survived and competed with other genres in a sacred city of Padang Indonesia, where metal and religion seemed to be unmatched. This research aims at understanding why heavy metal showed no significant progress despite its long existence in the city. An interview of five musicians from the five most popular metal bands in the city revealed that the metal music genre had struggled to survive for two reasons: the stigma of its negative influence on society and the failure of metal musicians in proving that metal symbols and lifestyle were irrelevant to the arts of metals. A SWOT analysis suggests that the metalheads need to utilize their subcultural capital by modifying their music using religious lyrics within the scene and by following social norms outside the scene.
\end{abstract}

Keywords: heavy metal, islamic city, padang, subcultural capital, SWOT 


\section{INTRODUCTION}

The relationship between metal, race, and religion has been an interest of recent scholars. The general agreement is that metal represents the extreme of the music world, given the negative publicity surrounding the heavy metal genre in both religious and secular circles. For example, the black metal scene was related to violent racism and embraced fascism (Kahn-Harris, 2004). However, the presumably claim that metal is identical to whiteness was disproved by Clinton and Wallach (2018) by showing a growing metal music fans across race and continents. In the Christian world, American Evangelicals have got involved in heavy metal to reach the American youth as part of their religious missions: real rebellion obeyed biblical authority and resistance to a sinful world (Luhr, 2005). Therefore, relationships between music and religion are contextual.

The genesis of heavy metal began on Friday the thirteenth, February 1970, when Black Sabbath, the first complete heavy-metal work by the first heavy-metal artists, was released by Vertigo Records and immediately became an addictive musical suspension of time. From Sabbath's time, heavy metal doubled in intensity to became power metal, then moved into thrash metal. The genre then crossed paths with different forms to become black metal, death metal, and other sorts of music, finding itself perpetually reborn. After a half-century, Black Sabbath remains the bedrock from which all heavy metal eternally rises (Christe, 2010). Metalhead is the term for fans and connoisseurs of metal music.

In Indonesia, heavy metal began in the mid of 70s triggered by the Deep Purple concert in Jakarta in 1975 (Safitri, 2013; Clinton \& Wallach, 2015). The first generation of metal came by the evolution of rock undergrounds such as God Bless, Gypsy, Giant Step, Super Kid, Terncem, and AKA. Although the first rock record label, Logiss Records, was formed in the 80s, the scene's foundation of metal bands established in the mid to late 1990s, and the scene had grown to approximately its present size by 2011 (James \& Walsh, 2019). Nowadays, Indonesia is a hotbed of heavy metal having more than 1,500 heavy metal bands across the archipelago, the highest number of head-slamming, ear-splitting heavy metal bands in Asia (Mutia, 2017).

In the early 1990s, Indonesian used the term underground to describe a cluster of rock music subgenres, including heavy metal. The term also referred to a method of producing and distributing cultural objects. By the year 2000, almost all urban areas had 
their local underground scene, the most prominent was in Jakarta, Yogyakarta, Surabaya, Malang, Bandung, Medan, Banda Aceh, and Denpasar. Each city in Indonesia, especially in Java, has its sub-genre mix (Wallach, 2008). For instance, Bandung is home for brutal death metal, Surabaya for power metal, and Jogjakarta for death metal. Thus, to understand metal in the Indonesian context, one must look deep into the interesting cities.

The interplay of Islam and music has a long tradition, and whether a particular type of music is allowed or forbidden is contextually dependent. Most Indonesian metalheads believe that religion and metal should not contradict because religion is a private matter and that a person's faith is irrelevant when participating in the metal scene. A similar reaction applies to the very public and hegemonic roles on how Islamic belief and practice play in Indonesian life. Metalheads want a safe place to pursue their subcultural interests and practices, free from the influences of the broader society (James $\&$ Walsh, 2019). In Islamic tradition in Indonesia, music which expectedly moves people harts closer to both God and Messengers are usually allowed regardless of its genres (Harnish \& Rasmusen, 2011). The evidence of the growing popularity of pop culture with lyrics promoting Islamic value in Indonesia supports the interplay.

However, the heavy metal genre is claimed by many as anti-Islamic, especially from Muslim hard-liners: when people think of heavy metal and moral panics, they usually think of accusations of Satanism, black magic, and violence (Clinton \& Wallach, 2005). It is not surprising since the birth of heavy metal by Ozzy Osborne and Black Sabbath related to the dark side of their lives (Christe, 2010). The dichotomy of Islam and metal was also pointed by Wallach (2011) that in Southeast Asia, amongst the socially alienated community members, young rural areas embrace Islamic radicalism, while metalheads opted to choose a musical form of resistance to status quo. Therefore, the three hijabers of Voice of Baceprot $(\mathrm{VoB})$ found themselves under constant death threats at their earlier career as metal music players (Cochrane, 2017).

The City of Padang in West Sumatra Province is part of the religious region of Minangkabau. It has regional philosophy of "Adat Basandi Syarak, Syarak Basandi Kitabullah (tradition hinges on sharia and sharia hinges on the Holy books)." In the city, heavy metal seems less popular, although other pop genres are easy to find. Konow (2002) 
pointed out that metal always received the least respect compared to other genres even though the genre sold millions of albums; many bands that were heavy metal shunned the term when describing their music, trying to distance themselves from it. Konow explained that being a heavy metal band came to be seen as limiting, and many elements of the genre would eventually cross the line into self-parody.

This research is the first, to the authors' knowledge, that attempts to analyze the existence and survival strategy of heavy metals in the city of Padang. The research questions seek to answer (i) how heavy metal came into the city of Padang, (ii) how the metal bands promote their work and compete with other genres, and (iii) what the best strategies are for the heavy metal to get popular in the city taking account the internal and external factors.

This paper divides into the following sections. The next section describes the methods of in-depth interviews followed by results and discussion about the history of metal music in Padang and how the metal survived and developed. This section is closed by the SWOT analysis and strategies of metal bands in Padang. The final section concludes.

\section{METHODS}

This qualitative research was conducted around June - August 2019 when the aforementioned second author wrote his undergraduate thesis about metalheads in Padang, where he is also a member of a heavy metal community in the city. After an initial survey of several music studios and places where the metal communities use to gather in Padang, five respondents from the five most influential metal bands in the city of Padang was selected to be interviewed: Honotjoroko, Zeal, Raze, Ocean Trenches, and Ardana. Formal interview and informal conversation with their representatives were then conducted.

The first interviewee was Broery Wirasadu, the guitarist of Honotjoroko, the oldest metal band in Padang. Broery is a very knowledgeable person in music and also a professional architect. The second was Utomo Setyadi Triman, Zeal's guitarist, who also owned 3 AM Studio, the most famous studio in Padang. Utomo's parents were both medical doctors, but he chose to study music in Australia. In 2017 Zeal performed a metal 
concert in Jakarta. The third interviewee was Meiza Pratama, nicknamed Cimay, a professional sound engineer. Cimay is a drummer of Ardana and also works as a sound engineer at 3 AM Studio. He has done many collaborated works with local artists and even foreign artists.

The fourth was the band manager of Raze, Fadhlan Yunanda, called Nanda, who also works as a journalist. Raze has conducted several different and extraordinary concepts that collaborated with musicians from Spain, Columbia, and Germany. Greece Media used to cover Raze, and their video clip entitled Evoke is available on YouTube. Their theme is humanitarian that invites listeners to rise against dictatorial rulers. The band has successfully managed to produce the physical album, clothes, and video clip.

The last one was Rizky Fajar, usually called Munir, the manager of Ocean Trenches. This band consists of young musicians who are very creative and aggressive. The band is widely known by young metal lovers in Padang and conducted a music tour in Java and Bali in January 2017 with the theme About This Life. They released their first album entitled "Before I Rewind" in 2016, and they were currently working on their second album.

\section{RESULT AND DISCUSSION}

Each respondent was interviewed on several occasions by using a list of questions. This section presents the summary all interviews and, if necessary, points to specific interviewee's responses.

How Did Metal Come to Padang?

The first question was on how, to the respondent's knowledge, heavy metal started and developed in the city. The following explanation was mainly from Participant "Broery," one of the knowledgeable metalheads.

Participant "Broery" told that around the 1980s and 1990s, when rock music was trendy, the city of Padang often held rock band festivals. This event was a competition with a choice of rock songs that were very difficult to play. One of the bands dared to play metal music on the race and finally won. Since then, metal music began to be known by many musicians in Padang. 
During the 1980s, magazines were the only media to find out information about heavy metal music, and the Rolling Stones was the most influential one. Not many metalheads at that time could get the Rolling Stones magazine in the beginning. However, after the metalhead became aware of metal's development in the world and followed the metal lifestyle, the situations were better.

In the 1990s, cassette store businesses were booming in this city, making music fans and metal communities naturally established. The customers of metal cassettes and CDs were usually middle and upper-class income of the population, in which listening to Western music was in part to showing social status (Wallach, 2008). Damar street near the Gramedia Book Store became the area where metal fans met since few good cassette stores located in the nearby areas. Moreover, local metalheads also created fanzines, locally produced metal magazines. Participant "Broery" explained further that the metal communities in Padang succeeded in making a metal music program known as Gigs, which the metal fans routinely performed. However, on some occasions, this event brought into chaos, frequent quarrels, abusive language, and alcohol. Thus, the majority of city dwellers consider this music genre terrible for society.

There are three large metal communities in Padang, namely, Gerilya Hitam in Permindo, Noize 13 in Jalan Jati, and Genderuwo Corpse in Indarung. These communities conducted activities such as conversations and exchanging information related to metal music. Wallach (2008) found that the way that underground music sold was direct selling among friends by using a mouth-word promotion, and hence music communities and events played such an important role. Participant "Broery" stated that, exclusively for the metalheads, the communities' basis was the mindset that metalheads saw people in the world deceived by the authorities. Thus, through metal music, musicians channeled their anger at the oppressing authorities. For example, Slow Death, a metal band from Surabaya, through their song "Crisis Prone Society," confronted that the social gap resulting from the 1998 crisis would trigger a state of social emergency in the country as people overburdened economically (Wallach, 2008).

The interaction amongst metal bands in the city of Padang is mainly for performance cooperation. Renting studios is costly, and metal music has not yet paid back. Fortunately, the metal personnel have their main job as their primary source of 
income. Thus, the community networks help the members sharing information and also sharing music tools and instruments. The communities also help to organize collaborative metal tours across cities in Indonesia and abroad. This type of social capital, in terms of network and relations, does help business promoting their products (Ridwan, 2016). In short, the communities have become the source of social capital to the metalheads in Padang.

The evolution of metal music in Padang the last ten years is an exciting phenomenon. The city, commonly known as an Islamic area, still generated several metal bands, as mentioned earlier. However, not a single metal band took a proper part in the music industry of the country. Thus, metal music practitioners in Padang have shown no significant changes during this period.

One exception, a metal band of Raze, originated from rural Talawi Sawahlunto, worth to mention, as told by Participant "Nanda." Raze, a metal band formed in October 2017 in Talawi, moved to Padang and started to produce albums in 2018. The founder of the group, Akbar Nicholas, took advantage of his background in working on the field of tourism to conduct international affiliation. Through this affiliation, Raze was finally able to work with foreign photographers and videographers. Moreover, their works were reviewed and promoted by producers and reviewers from foreign countries such as Spain, Greece, America, and Hong Kong.

Raze implemented this international affiliation concept in terms of both production and promotion. In production proses, Raze collaborated with Bellyfire Production, a company that was also a contributor to CNN and NBC in America. This company provided some footage from Colombia that was later on being used on Raze's music video entitled Evoke, which is available on the Youtube platform. Raze also worked together with Adriana Dominguez, a photographer and a journalist for Barcelona-based El Periodico Magazine. She provided her photos as a cover of Raze's first mini-album.

On the promotion side, Gem City Studio, a music label from Tennessee, USA, invited Raze to be interviewed during a music program called Eat This Metal. Besides, a webstream music radio from Greece and Unite Asia, and an online music promotion from Hong Kong also streamed and promoted the band. With their excellent work and international affiliation, Raze had proved a significant change within roughly one and a half years as the fastest growing metal band in Padang. 


\section{How Do You Promote Metal?}

When asked on how they promoted their music in the city, each respondent's answers were not varied. Participant "Nanda," who has got a long involvement in the world of metal in Padang, revealed that the first key to market heavy metal was to use an online platform such as Sound Cloud, Band Camp, YouTube. As the metal in Padang has not yet as popular as the other genres, online marketing would make the albums known to the fans. Besides, distributing physical records free of charge to the fans also helps to promote.

The second key to success in promoting heavy metal in Padang was to have healthy and robust teamwork. The band must have come from a long-term relationship amongst its personnel. Some might have had previous groups, and they knew each other through some music events. These shared interests and long-term relationships were the basis for building a strong team to compete in the market. As in Padang, Wallach (2011) showed that these shared interests worked as well for metal bands in Ngawi, a small town in East Java, where the groups had a high quality due to a healthy and robust network: they won several competitions in the surrounded cities.

\section{What are the difficulties in Promoting the Work?}

Asked about the difficulties of promoting work, the majority of respondents realized their weak network and poor communication skills as the main problem. Participant "Munir," the manager of Ocean Trenches, stated that "lacks of personal relations in promoting work, weak communication abilities with the media, and poor album design will hamper the distribution." Besides, some other respondents mentioned that there was a long-term negative stigma to metal music because of some rude lyrics and lack of socially acceptable appearance of the musicians. As a consequence, most listeners avoided heavy metal even though many of the songs can increase people's awareness of social problems in the community that are unrevealed to many people."

Most respondents believed that friendships arisen from listening metal were an added value to the listeners. The music, they found, could expand its fans' horizons and exposed them to the existing social inequalities in the community. When asked whether the majority of Padangness who listen to metal music changed psychologically, almost all respondents said that metal music might change their mindset and psychology. Some of 
the metal lyrics do insulting, derogatory, emotional, and a surge of resentment as a protest to injustice phenomena they see in the world. As a consequence, some audiences might become brave to criticize the government after seeing unequal treatment in the community. However, some others behaved rudely and inconsiderate, which resonated with a more negative stigma towards this music.

Another difficulty in promoting metal is the hardness to get a live concert license from the authority. Participant "Cimay" stated that "heavy metal has three requirements to hold a concert: location, open invitation, and the bands. Unfortunately for the metal, it is complicated to get a permit to hold a concert because heavy metal presumably causes chaos." According to some studies, the police charged high fees to grant permission to hold a concert to maintain its security since the metal scenes are vulnerable to chaos. For example, in 2011, there were eleven attendees of the extreme metal community in Bandung who were crushed to death (James \& Walsh, 2015). Therefore, metal music is relatively discouraged from using public open spaces to carry out their concerts, and the license was often only given in the last minutes. Cimay added that even though some reputable event organizers invited a metal band to perform, they did not get paid. In other words, they only play for their album promotion.

However, the metal programs termed "underground" do take place every month in Padang. This phenomenon is similar to the black market in economic terminology. The underground concerts in the city of Padang have occurred in venues such as the Padang State University Hall, Agus Salim Stadium, and Imam Bonjol Park.

What Do You Think About Pop Music vs. Metal?

When asked their view about popular music compared to heavy metal, respondents' response was objective. Most of the respondents realized that metal could not provide a decent life in the city right now. Participant "Nanda" revealed:

If you want to play music for a living, heavy metal is not an option. All cafes and restaurants in this city currently only hire popular music. It is almost impossible for metal music to accompany cafe customers, say, for dinner. Similarly, no wedding ceremony retains heavy metal bands because of the wedding's atmosphere. In rural areas or outside the city, Dangdut or Solo Organ are more accessible for weddings. 
Participant "Utomo" also added that it was tough to win the popular bands in the market, and for metal to defeat them, metal musicians must be able to make psychological connections with their fans. Close relations with the community will have a big influence on the existence of a band.

\section{What are the Best Ways to Get Customers?}

The metal bands in the city of Padang have routine activities similar to other groups. They also continue to grow, not just a temporary hobby. Even some of the country's metal bands originated from the City of Padang, such as Ocean Trenches.

Most respondents explained that metal bands usually got a paid contract with well-known cigarette companies in Padang because the themes of the company's event matched with the floors, mostly smokers. When asked how to get loyal customers, Participant "Munir" answered: "by making an online profile, produce albums, joining metal communities, and carrying out tours." Nowadays, metal music plays not only on special metal events, but it begins to perform at everyday music events.

In addition to their constant promotion, the metal communities hope society give the metal the same respect as they give to other genres. Participant "Broery" expressed:

Padang people must realize that metal is a genre of music, not a cult. People tend to judge metal has a bad influence on the community since their musicians and their followers have a tattoo, piercing, wearing black clothes, and singing loud and noisy. However, metals use those attributes only to support their understanding of the flow of music, just like other types of music that have their style in expressing their lyrics.

There also seems that metalhead in Padang has not yet had a long-term mission and agenda. As a consequence, branding and positioning have not yet a precise cut. Whether metal will be closer to the community or to be independent has not been seen. Branding and position in the world of metal play a crucial role in making music accessible. For example, Jihad and Saffar metal bands in Bandung are well known because they positioned themselves as bands of Muslims rather than Muslim bands (James \& Walsh, 2015). 
SWOT Analysis and Strategies

The interview results were taken to form a SWOT analysis for the heavy metal in Padang to identify the elements of internal strengths and weaknesses and the external opportunities and threats. The presentation was limited to three main items for each element and formulated strategies related to those components.

Three strengths of heavy metal in Padang was identified. First, they have strong bonding relationships amongst the band communities. This relationship forms their cultural capital as in Khan-Harris (2004 \& 2007), where the members do not consider gender differences or races as crucial factors. Second, the metal community in Padang has strong ties with their fellow fans. The trademark of rebellion to the oppressors would even bond the metal communities and make them have a fighting spirit. Participant "Nanda" pointed out that they delivered messages quickly through song lyrics embodied by social, political, and other sensitive themes. Third, Padang has several metal bands, and most of them are well managed, in addition to their close relationship.

Three main weaknesses appeared, according to respondents. First, most general audiences do not understand the songs because of their unfamiliarity; only targeted people enjoy it. Second, the lyrics used are too frontal and offensive to many parties. Third, the band members have fewer skills dealing with the law of contract. Participant "Utomo" noticed their lack of understanding about the contract system with the labels and producers.

The three opportunities from the outer side of the bands are as follows. First, several events, including corporate events such as cigarette companies, take place every year that usually invites metal bands. Second, Padang people tend to care not about the types of music genres but the lyrics. As stated before, as long as the songs are acceptable or making hearts closer to God, people do not care how these lyrics are to sing. Third, there opens the possibility of getting contracted with a label or producer. Participant "Cimay," for instance, has done many collaborated works with local artists and even foreign artists.

The three main threats are from competition, law enforcement, and permits. First, competitors from other genres also compete for the same market. Participant "Utomo" noticed the difficulties of competing with popular music in Padang. Second, there are many practices of piracy due to weak law enforcement in the country. Third, the permits to perform are hard to get from the authority because of the stigma that the heavy metal shows may cause chaos. 
Using those elements, the strategies was formulated taking into account of the requirements the metal bands must-have. Kahn-Harris (2007) introduced the terms of "mundane" and "transgressive" to subcultural capital, introduced earlier by Thornton (1995). James and Walsh (2015) emphasized that the two types of subcultural capital were required for the metal scene to survive. The idea is that to gain power, status, and wealth within the scene, an individual or group needs to struggle by simultaneously behaving mundanity as well as transgression. In the metal scene, the two types of subcultural capital can be achieved within the scene and outside the scene. For instance, the metalheads' ethical behavior in daily life by obeying rules and regulations is a mundane act to gain sympathy. Their use of dirty and sharp lyrics during a performance by using metal accessories is a transgressive act to gain power and status. Nevertheless, the ingredients and relative importance between the two are subjective and culturally contingent.

Based on SWOT analysis, three strategies was formulated to make heavy metal survive and accessible in the city of Padang. First, metal bands and communities have to keep promoting their work through social media. Participant "Broery" found this strategy worked with his group. However, not all work needs to display on the internet. So, if a label is interested in publishing, some work is still not yet launched to the public. The experience of Raze having collaborated internationally also needs to continue.

Second, the metal groups must apply copyright on each of their work and hire lawyers to prevent the stealing of work for business purposes. A little pirate is negligible, and it can take as a form of free promotion. Numerous artists are coming to popularity after their work had been illegally distributed, such as Inul Daratista, a superstar dangdut artist, who endured condemnation in the 2000s because of her suggestive and erotic "drilling" dance moves (Harnish \& Rasmussen, 2011).

Third, metal bands need to adjust to the social norm. Participant "Utomo" mentioned that metal bands required to soften the lyrics to the acceptable level from society's perspective. So, chaos may be minimum. More important is to modify the songs to adopt Islamic values and then play with a metal genre. Also, the metalheads need to cut a lifestyle that is not suitable for norms and culture needs. Metalheads in Padang needs to follow the steps taken by their fellow female metal band Voice of Baceprot (VoB) from Garut, West Java. The VoB wears typical Islamic customs while headbanging, without 
following known as metal lifestyles. By wearing hijabs and taking a prayer break during a festival, metalheads could prove that the devil's presumed music did not need to clash with Islamic identity (Mutia, 2017).

By simultaneously applying these strategies, heavy metal will be accepted by Padang people as one of their favourite music. Moreover, these strategies will be sufficient to satisfy the required mundane and transgressive subcultural capital.

\section{CONCLUSION}

Heavy metal is struggling in the City of Padang despite their long existence. That conclusion is from an in-depth interview with five members of five prominent heavy metal bands in the city. Two opposite reasons for their struggle emerge from this research. On the one hand, the interviewees felt that majority of the city dwellers had judged them to have a bad influence on society by looking at their physical appearance. On the other hand, the musicians have an excessive pride identified as metalheads with all symbols and lifestyles from the worlds of metal. Moreover, instead of adjusting their behavior to the standard norms of the city, they required the society to understand their behavior and possibly accept it.

The strength of heavy metal in Padang is that it has a strong bond community as social capital. However, the number of members is too slow to increase. Thus, if the musicians fulfil the required types of subcultural capital, the metal genre gains acceptance. Metalheads need to adjust to the level that the majority of residents can accept their music and behaviour. One prominent way is to challenge the massively noisy music to use pious Islamic lyrics.

\section{REFERENCES}

Christe, I. (2010). Sound of the Beast: The Complete Headbanging History of Heavy Metal. EPub Edition. Harper Entertainment.

Clinton, E., \& Wallach, J. (2015). Recoloring the Metal Map: Metal and Race in Global Perspective. Modern Heavy Metal: Markets, Practices, and Cultures International Academic Conference 2015.

Cochrane, J. (2017, September 2). In Indonesia, 3 Muslim Girls Fight for Their Right to Play Heavy Metal. The New York Times. Available online from: https://www.nytimes.com/2017/09/02/world/asia/indonesia-voice-ofbaceprot-girls-heavy-metal.html [Accessed April 17, 2020]. 
Harnish, D., \& Rasmussen, A. (2011) The World of Islam in the Music of Indonesia. In D. Harnish \& A. Rasmussen (ed) Divine Inspirations: Music and Islam in Indonesia. Oxford University Press.

James, K., \& Walsh, R. (2015). Bandung Rocks, Cibinong Shakes: Economics and Applied Ethics within the Indonesian Death-metal Community. Musicology Australia, 37(1), 28-46.

James, K., \& Walsh, R. (2019). Religion and heavy metal music in Indonesia. Popular Music, 38(2), 276-297.

Kahn-Harris, K. (2004). The "Failure" of Youth Culture: Reflexivity, Music and Politics in the Black Metal Scene. European Journal of Cultural Studies, 7(1), 95-111. https://doi/10.1177/1367549404039862.

Kahn-Harris, K. (2007). Extreme Metal: Music and Culture on the Edge. Berg.

Konow, D. (2002). Bang Your Head: The Rise and Fall of Heavy Metal. Three River Press.

Luhr, E. (2005). Metal Missionaries to the Nation: Christian Heavy Metal Music, "Family Values," and Youth Culture, 1984-1994. American Quarterly, 57(1), 103-128.

Mutia, R. (2017, August 24). Headbangers in Hijabs: Inside Indonesia's Heavy Metal Scene. South China Morning Post. Available online: https://scmp.com/culture/music/article/2108130/headbangers-hijabs-insideindonesias-heavy-metal-scene [Accessed April 17, 2020]

Ridwan, E. (2016). Essays on Microfinance, Entrepreneurship, and Social Capital in Developing Economies (Publication Number 10153195). [Doctoral Dissertation, Indiana University Bloomington]. ProQuest Dissertations Publishing.

Safitri, I. (2013, Mei 13). Sejarah Gemuruh. Majalah Tempo. Available online from: https://majalah.tempo.co/read/selingan/142643/sejarah-gemuruh [Accessed April 17, 2020].

Thornton, S. (1995). Club Cultures: Music, Media, and Subcultural Capital. Polity Press.

Wallach, J. (2005). Underground Rock Music and Democratization in Indonesia. World Literature Today, 79(3-4), 16-20.

Wallach, J. (2008). Modern Noise, Fluid Genres: Popular Music in Indonesia, 1997-2001. The University of Wisconsin Press.

Wallach, J. (2011). Unleashed the East: Metal Music, Masculinity, and "Malayness" in Indonesia, Malaysia, and Singapore. In J. Wallach, H. Berger, \& P. Greene (ed). Metal Rules the Globe: Heavy Metal Music Around the World. Duke University Press.

Wallach, J., \& Clinton, E. (2013). History, Modernity, and Music Genre in Indonesia: Popular Music Genres in the Dutch East Indies and Following Independence. Asian Music, 44(2), 3-23. 